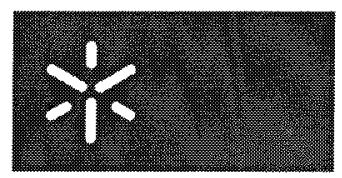

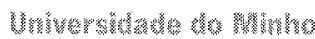

[Cl-23]

Pais, J.C., Pereira, P.A.A., Azevedo, M.C.M., Picado-Santos, L.G.

"The influence of fine aggregate on the bituminous mixture mechanical behaviour"

Sixth International Conference on the Bearing Capacity of Roads, Railways and Airfields, Lisboa, Portugal, 2002, p. 923-932 


\section{Brantig Paparín of ioacis, Rallways and Afritelis}

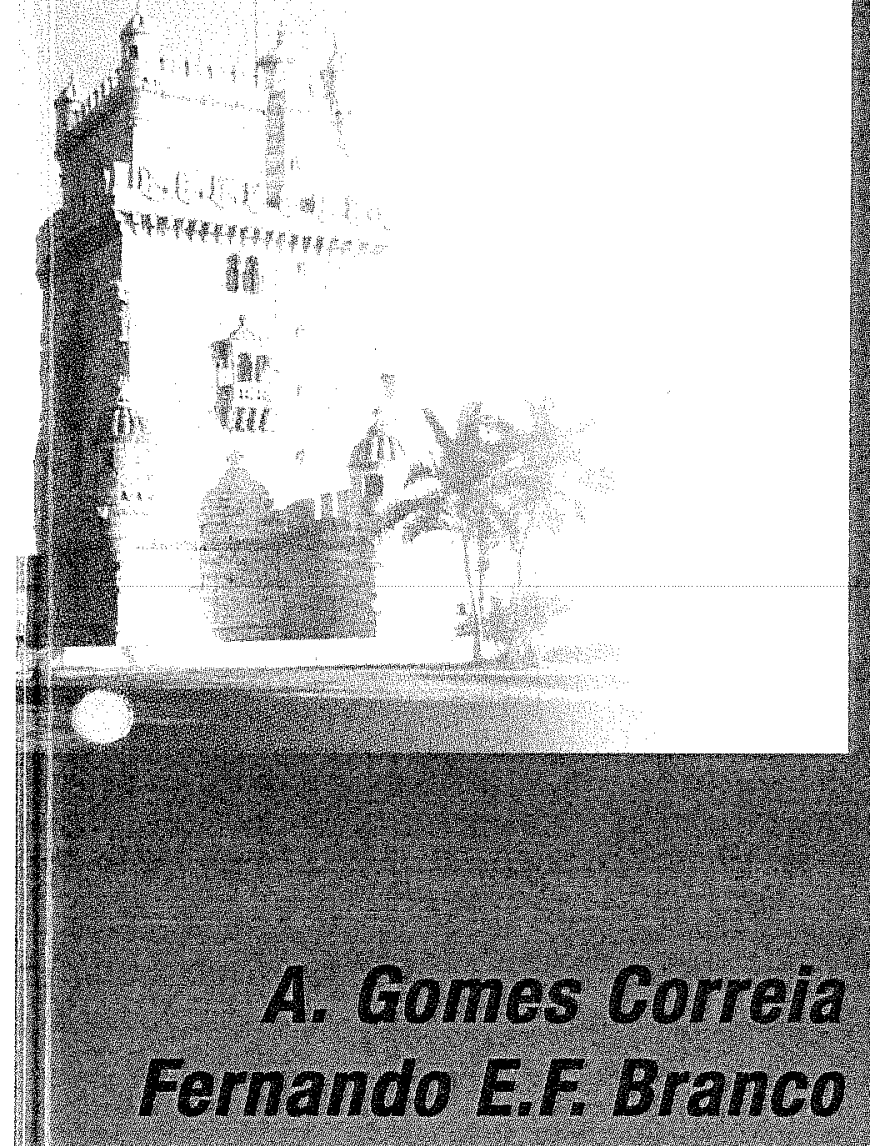




\section{Table of Contents}

Introduction

A. Gomes Correia, Ivar Horvli

Preface

Fernando E.F. Branco

Organization

\section{Asphalt mixtures}

Sample Preparation Methods, Geometry and Temperature

Control for Dynamic Shear Rheometers

G.D. Airey, A.E. Hunter, B. Rahimzadeh

Evaluation of the Linear and Non-Linear Viscoe
of Bituminous Binders and Asphalt Mixtures

G.D. Airey, B. Rahimzadeh, A.C. Collop

Experimental Procedures for Evaluating Asphalt Mix Stability Using the Superpave Gyratory Compactor

F.M. Bayomy, S. Dessouky, E. Masad

Assessment of the Durability of High Modulus Base (HMB) Materials

Rheological Behaviour of Bitumens Modified with Reactive Polyurethanes 
Testing Adhesion between Bitumen and Aggregate with the Rolling Bottle Test and the Boiling Test

T. Jørgensen

Advantages of Using Asphalt Emulsion Mixes in Cold Climates

J.-M. Konrad, J. Cummings, M. Muma

Permanent Deformation of Bituminous Mixes: Monotonous and Cyclic Contributions

M. Neifar, H. Di Benedetto, J.M. Piau, H. Odeon

The Influence of Fine Aggregate on the Bituminous

Mixture Mechanical Behaviour

J.C. Pais, P.P.A. Pereira, M.C.M. Azevedo, L.G. Picado-Santos

Semi-flexible Materials for Heavy-Duty Pavements

J. Sundahl, J. Hede

Influence of Aggregate Characteristics on Asphalt Mixture

Properties and Performance

M. Tia, B.E. Ruth, R. Birgisson

\section{Unbound granular materials}

Serviceability Design of Granular Pavement Materials

G.K. Arnold, A.R. Dawson, D. Hughes, S. Werkmeister, D. Robinson

of Field Measurements and Laboratory Investigations

- Comparisons

J. Aurstad, I. Hoff

Origin, Usage and Production of Unbound Granular Materials

for Road Construction

G. Bjarnason, H.G. Johansson, S. Davitt

Dynamic Triaxial Testing of Unbound Granular Base Course Materials

S. Erlingsson, B. Magnusdottir

Modeling Unbound Granular Material Response from

Laboratory and Field Measurements

G. Gidel, D. Breysse, A. Denis, P. Hornych

Light Weight Aggregate (LWA) Used in Road Pavements

I. Hoff, A. Watn, E. Øiseth, A. Emdal, K.O. Amundsgård

Cost 337 - Unbound Granular Materials for Road Pavements 
Effect of Seasonal Changes on Strength and Deformation Properties of Unbound and Bound Road Aggregates

T. Saarenketo, P. Kolisoja, N. Vuorimies, H. Peltoniemi

Effect of Material Quality and Compaction on the Mechanical Behaviour of Base Course Materials and Pavement Performance

The Development of a Permanent Deformation Design Model for Unbound Granular Materials with the Shakedown-Concept

S. Werkmeister, R. Numrich, F. Wellner

\section{Soils}

Threshold Stress and Asymptotic Stiffness of UK Clays in the

Repeated Load Triaxial Test

M.W. Frost, P.R. Fleming, C.D.F. Rogers

Subgrade Characterization for Low Volume Road Design Using

"Critical Period" Concept

N. Garg, M.R. Thompson

Alternative Methods of Determining Resilient Modulus of Subgrade Soils Considering Deformational Characteristics

D.S. Kim, G.C. Kweon

Modeling the Resilient Modulus of Soils

B. Ni, T.C. Hopkins, L. Sun, T.L. Beckham

Evaluating Compaction of Tropical Soils Using Soil Stiffness

P.S.K. Ooi, J. Pu

Moisture Related Problems in Stabilized Materials

I.M. Syed, T. Scullion

Directional Dependency of Modulus and Deformation Characteristics

of Geofiber Stabilized Sands

E. Tutumluer, I.T. Kim, R.L. Santoni

\section{Case histories}

Maintenance and Repair of Airfield Apron Rigid Pavements 
Effect of Landing Gear Spacing on the Surface Deflection

Response of Airport Pavements

N. Garg, M. Dong

Flexible Composite Pavement Evaluation Incorporating Bond between Layers

B.A. Hakim

Innovative Evaluation Methodology Reduces Maintenance Costs at

Copenhagen Airport

J.C.H. Hede, J. Andersen, H.H. Bünner

Pavement Design Considerations for Container Terminal Areas: A Case Study

P. Herman, W. Haegeman, W. De Corte, E. De Winne

LINTRACK Rutting Research Project - ALT Testing Program

L.J.M Houben, C.H. Vogelzang, A.E. van Dommelen

Some Observations of Base Course Performance during Accelerated

Pavement Testing

V.C. Janoo, E.R. Cortez

Effects of Different Tyre Mounts on the Fatigue Behaviour of

a Thick Bituminous Pavement

H. Ódeon, C. Penant, J.-M. Piau

Importance of Complcmenting Index Tests with Mechanical Tests

for Granular Materials Assessment: A Case Study

A. Petkovsek, A. Gomes Correia

\section{Railways}

Repeated Load Aggregate Degradation

V.A. Diyaljee

Effects of Cyclic Loading Conditions on the Behaviour of

Railway Track in the Laboratory Model Tests

D. Hirakawa, H. Kawasaki, F. Tatsuoka, Y. Momoya

Performance Tests and Basic Design on Solid Bed Track on Asphalt Pavement

Y. Momoya, K. Ando, T. Horiike

Tests of Treated Subgrades and Capping Layers using

Cementitious Binder in Railtrack Infrastructures

A. Quibel, M. Mudet

Dimensionless Sensitivity Diagrams in Mechanistic Railway Design

K.A. Skoglund

Author Index 


\title{
The Influence of Fine Aggregate on the Bituminous Mixture Mechanical Behaviour
}

\author{
J.C. Pais \& P.P.A. Pereira \\ University of Minho, Department of Civil Engineering, Guimarães, Portugal \\ M.C.M. Azevedo \\ $C A \& M D, L d a$, Lisboa, Portugal \\ L.G. Picado-Santos \\ Depatment of Civil Engineering of the University of Coimbra, Coimbra, Portugal
}

ABSTRACT: This paper presents the results obtained during the implementation of a new laboratory tests to evaluate the asphalt-aggregate adhesion. Those tests performed on the mixture mastic, are based on tension and shearing properties of the mixture. The calibration and validation of those laboratory tests was made comparing the performance of mastic specimens with the fatigue and permanent deformation of corresponding mixtures. This paper presents the fatigue and permanent deformation results of bituminous mixtures used in wearing and base courses. For each type of mixture, five mixtures were defined, by changing the gradation curve (from more to less fine aggregates). All mixtures were produced and compacted in laboratory. Specimens for tests were obtained by cored and sawed from compacted slabs. For stiffness and fatigue, tests were executed on four point bending beam on controlled strain, whereas for permanent deformation tests were the repetitive simple shear test at constant height.

KEYWORDS: Stiffness modulus, phase angle, fatigue life, permanent deformation

\section{INTRODUCTION}

A new laboratory tests for the characterization of the coarse aggregate bond to the asphalt mastic is being developed at the University of Minho. Those tests evaluates the tensile and shear properties of the bond region of a bituminous mixture and correlates the results with tensile fatigue cracking and permanent deformation resistance of the whole bituminous mixture.

One of main objectives of that study is to understand in which way the mastic gradation influence the bituminous mixture properties evaluated using the new tension and shear laboratory tests.

Laboratory tests (tension and shear) on mastic specimens with and without course aggregates have been executed at the University of Minho to simulate the adhesion between the binder and the aggregate. For this study, mastic was defined as the material that is bond to course aggregate. A sieve analysis of the material bond to the different course aggregate was performed which allow to define some mastic gradations and binder content for each course aggregate size.

These mastics with different aggregate gradations and binder content were subjected to tension and shear tests to evaluate the adhesion between the bitumen and the aggregate.

Some important conclusions were obtained based only on those tests performed on mastic specimens. 
So, to validate those conclusions, standard fatigue and permanent deformation tests were executed on bituminous mixtures with different aggregate gradations, correlated with the one used in the mastic specimens.

\section{EXPERIMENT DESIGN}

\subsection{Materials}

In this study two types of bituminous mixtures were used. A dense graded bituminous mixture for base courses and a bituminous mixture for wearing courses, following the Portuguese normalization. Based on each aggregate gradation, more four mixtures were defined. Two mixtures where the gradation curve is below and two mixtures where the gradation curve is above the gradation curve defined by the Portuguese normalization. These four gradation curves were defined changing the amount of aggregates in the sieves \#20, \#40, \#80 and \#200.

Thus, the gradation curve proposed by the Portuguese normalization for wearing courses was used to produce mix number 1 (more fines) to 5 (less fines), as presented in Table 1, and the gradation curve proposed by the Portuguese normalization for base courses was used to define mixes 6 (more fines) to 10 (less fines), as presented in Table 2. These gradation curves can also be observed in Figure 1 and Figure 2, respectively for wearing and base courses.

Table 1. Aggregate gradations used for wearing courses bituminous mixtures.

\begin{tabular}{lcrrrrr}
\hline Sieve & $\begin{array}{l}\text { Diameter } \\
(\mathrm{mm})\end{array}$ & \multicolumn{5}{l}{ Percentage of material passing } \\
\cline { 3 - 7 } & & Mix 1 & Mix 2 & Mix 3 & Mix 4 & Mix 5 \\
\cline { 3 - 7 } & & 100.0 & 100.0 & 100.0 & 100.0 & 100.0 \\
$3 / 4^{\prime \prime}$ & 19,000 & 84.0 & 84.0 & 84.0 & 84.0 & 84.0 \\
$1 / 2^{\prime \prime}$ & 12,500 & 71.3 & 71.3 & 71.3 & 71.3 & 71.3 \\
$3 / 8^{\prime \prime}$ & 9,500 & 55.4 & 55.4 & 55.4 & 55.4 & 55.4 \\
No. 4 & 4,750 & 36.4 & 36.4 & 36.4 & 36.4 & 36.4 \\
No. 10 & 2,000 & 30.6 & 29.7 & 23.7 & 24.7 & 22.4 \\
No. 20 & 0,850 & 27.0 & 25.5 & 15.6 & 17.2 & 13.3 \\
No. 40 & 0,425 & 15.7 & 14.0 & 10.5 & 9.3 & 7.1 \\
No. 80 & 0,180 & 8.7 & 6.9 & 7.4 & 4.3 & 3.3 \\
No. 200 & 0,075 & 0.0 & 0.0 & 0.0 & 0.0 & 0.0 \\
Rest & & & & & & \\
\hline
\end{tabular}

Table 2. Aggregate gradations used for base courses bituminous mixtures.

\begin{tabular}{lcrrrrr}
\hline Sieve & $\begin{array}{c}\text { Diameter } \\
(\mathrm{mm})\end{array}$ & \multicolumn{5}{c}{ Percentage of material passing } \\
\cline { 3 - 7 } & & Mix 6 & Mix 7 & Mix 8 & Mix 9 & Mix 10 \\
\hline $1^{\prime \prime}$ & 25,000 & 100.0 & 100.0 & 100.0 & 100.0 & 100.0 \\
$3 / 4^{\prime \prime}$ & 19,000 & 96.2 & 96.2 & 96.2 & 96.2 & 96.2 \\
$1 / 2^{\prime \prime}$ & 12,500 & 80.0 & 80.0 & 80.0 & 80.0 & 80.0 \\
$3 / 8^{\prime \prime}$ & 9,500 & 72.5 & 72.5 & 72.5 & 72.5 & 72.5 \\
No. 4 & 4,750 & 59.2 & 59.2 & 59.2 & 59.2 & 59.2 \\
No. 10 & 2,000 & 42.9 & 42.9 & 42.9 & 42.9 & 42.9 \\
No. 20 & 0,850 & 36.3 & 35.2 & 30.8 & 28.4 & 25.7 \\
No. 40 & 0,425 & 32.3 & 30.4 & 23.1 & 19.1 & 14.5 \\
No. 80 & 0,180 & 18.5 & 16.7 & 13.7 & 10.2 & 7.7 \\
No. 200 & 0,075 & 9.8 & 8.1 & 7.9 & 4.6 & 3.5 \\
Rest & & 0.0 & 0.0 & 0.0 & 0.0 & 0.0 \\
\hline
\end{tabular}


For each mixture studied, the optimum binder content was calculated using the formula based on the specific surface of the aggregates developed by Duriez, M. (1950):

$$
t_{b}=\alpha \times k \times \sqrt[5]{\Sigma}
$$

where $t_{b}=$ binder content; $\Sigma=$ ratio between the bulk density of the aggregates and the; $\mathrm{k}=$ function of the binder content of the mixture and $\Sigma=$ depends on the grading curve of the aggregates. Table 3 presents the binder content for each mixture, given in percentage of aggregate weight.

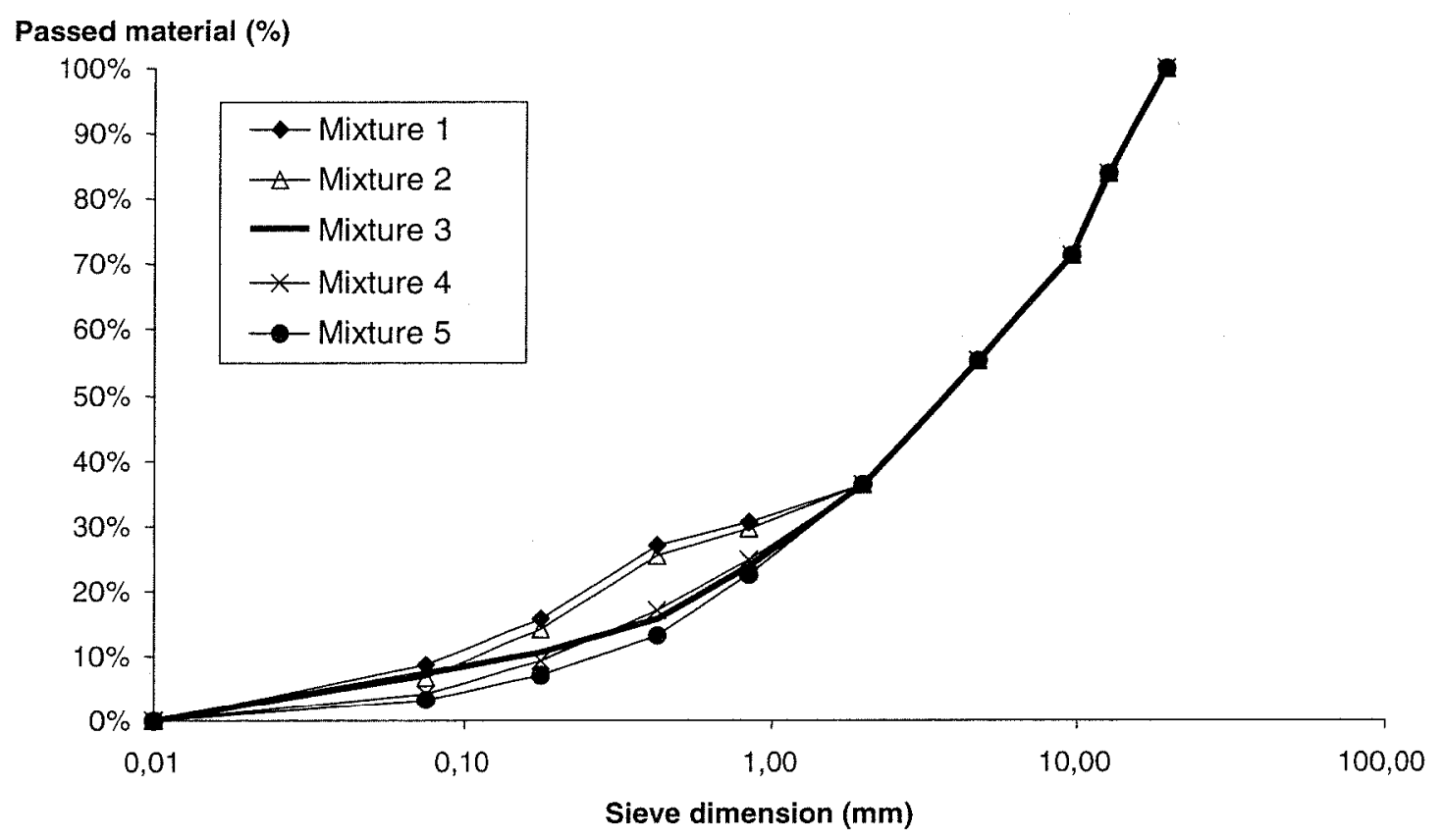

Figure 1. Aggregate gradation curve for wearing course bituminous mixtures.

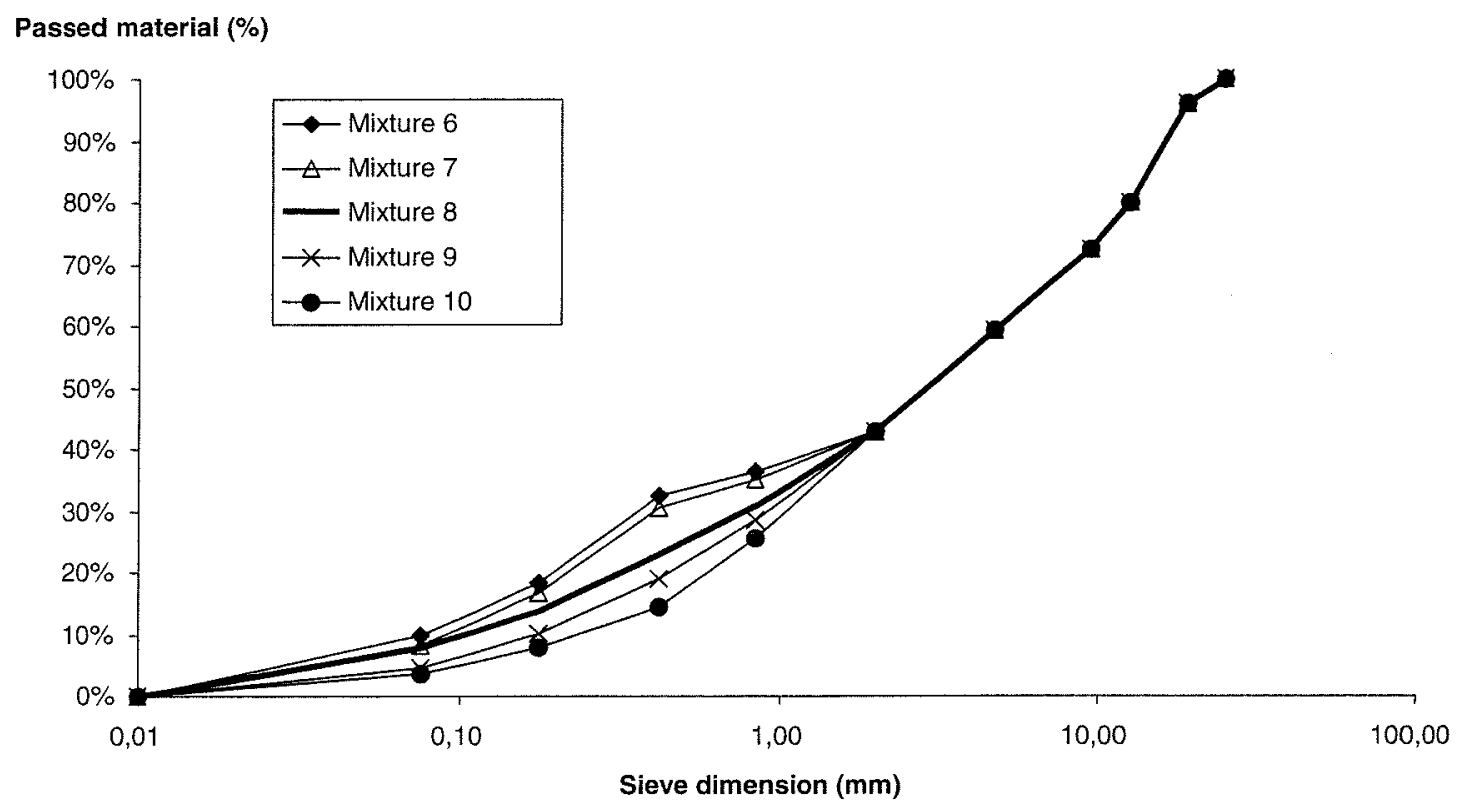

Figure 2. Aggregate gradation curve for base course bituminous mixtures. 
Table 3. Binder content (in percentage of aggregate weight) for the mixtures used in this study.

\begin{tabular}{llll}
\hline Mix & Binder content $(\%)$ & Mix & Binder content (\%) \\
\hline 1 & 6.0 & 6 & 6.0 \\
2 & 5.8 & 7 & 5.8 \\
3 & 5.8 & 8 & 5.8 \\
4 & 5.4 & 9 & 5.3 \\
5 & 5.2 & 10 & 5.1 \\
\hline
\end{tabular}

Table 4. Air-void content for the mixtures used in this study.

\begin{tabular}{llrl}
\hline Mix & $\begin{array}{l}\text { Air-void } \\
\text { content (\%) }\end{array}$ & Mix & $\begin{array}{l}\text { Air-void } \\
\text { content (\%) }\end{array}$ \\
\hline 1 & 1.3 & 6 & 4.9 \\
2 & 2.9 & 7 & 7.4 \\
3 & 1.2 & 8 & 4.0 \\
4 & 5.0 & 9 & 6.6 \\
5 & 7.7 & 10 & 10.8 \\
\hline
\end{tabular}

\subsection{Specimen Preparation}

To produce the specimens, the bituminous mixtures were produced and compacted in laboratory. The aggregates were heated at $178^{\circ} \mathrm{C}$ and for the bitumen (PEN 50/70) the temperature was $150^{\circ} \mathrm{C}$. After mixing, the mixtures were placed in an over at $135^{\circ} \mathrm{C}$ during 4 hours to be subjected to the conditioning recommended by SHRP-A003A (Tayebali et al. 1994). The compaction was made with a lightweight vibratory steel roller in a steel coated wood mold. The amount of mixture that was placed in the mold was always the same to control the air void content but in some mixtures, part of the mixture could not be fitted in the mold.

One day after compaction the slab was extracted from the mold and some days later the slab was sawed and cored to produce beams and cylindrical specimens used in fatigue tests and shear tests. The air-void content was measured in all specimens and the average for each mixture is presented in Table 4.

\section{STIFFNESS MODULUS AND PHASE ANGLE}

The bituminous mixtures exhibit linear-viscoelastic behavior as such that their response is time of loading and test temperature dependent. This behavior is represented by the following relationship:

$$
S_{m i x}=\frac{\sigma}{\varepsilon}(t, T)
$$

where $S_{\text {mix }}=$ is the mixture stiffness, $\sigma=$ is the stress level, $\varepsilon=$ is the strain level, $t=$ is the time of loading and $\mathrm{T}=$ is the test temperature.

The material stiffness measures the ability to spread the traffic loads over an area. This parameter represents an important rule in the design of pavements once the design strain level is a function of the material stiffness.

The stiffness modulus and the phase angle were measured using a frequency sweep test. All the frequency sweep tests of this study were executed at a strain level of $150 \mathrm{micros} \mathrm{mm} / \mathrm{mm}$, and at $10,5,2,1,0.5,0.2$ and $0.1 \mathrm{~Hz}$. 


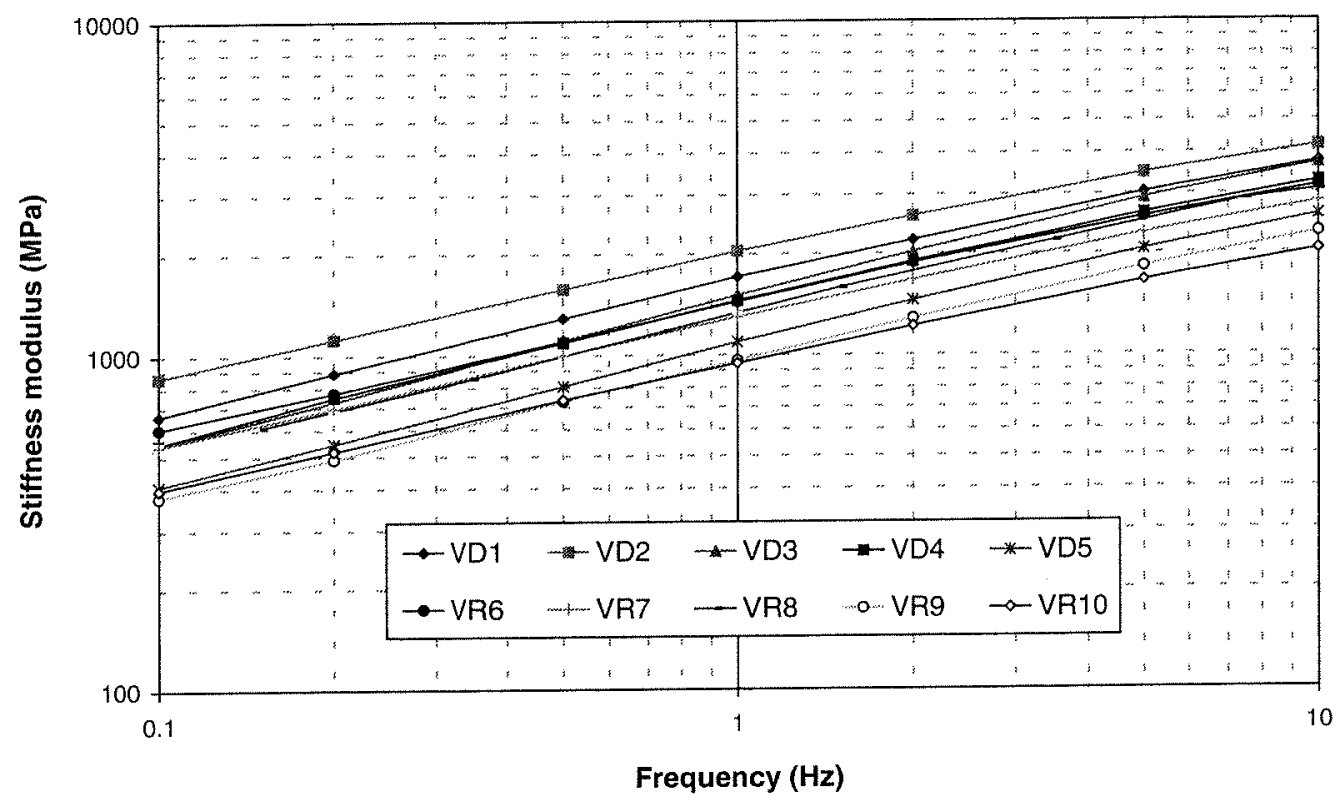

Figure 3. Stiffness modulus plotted against frequency.

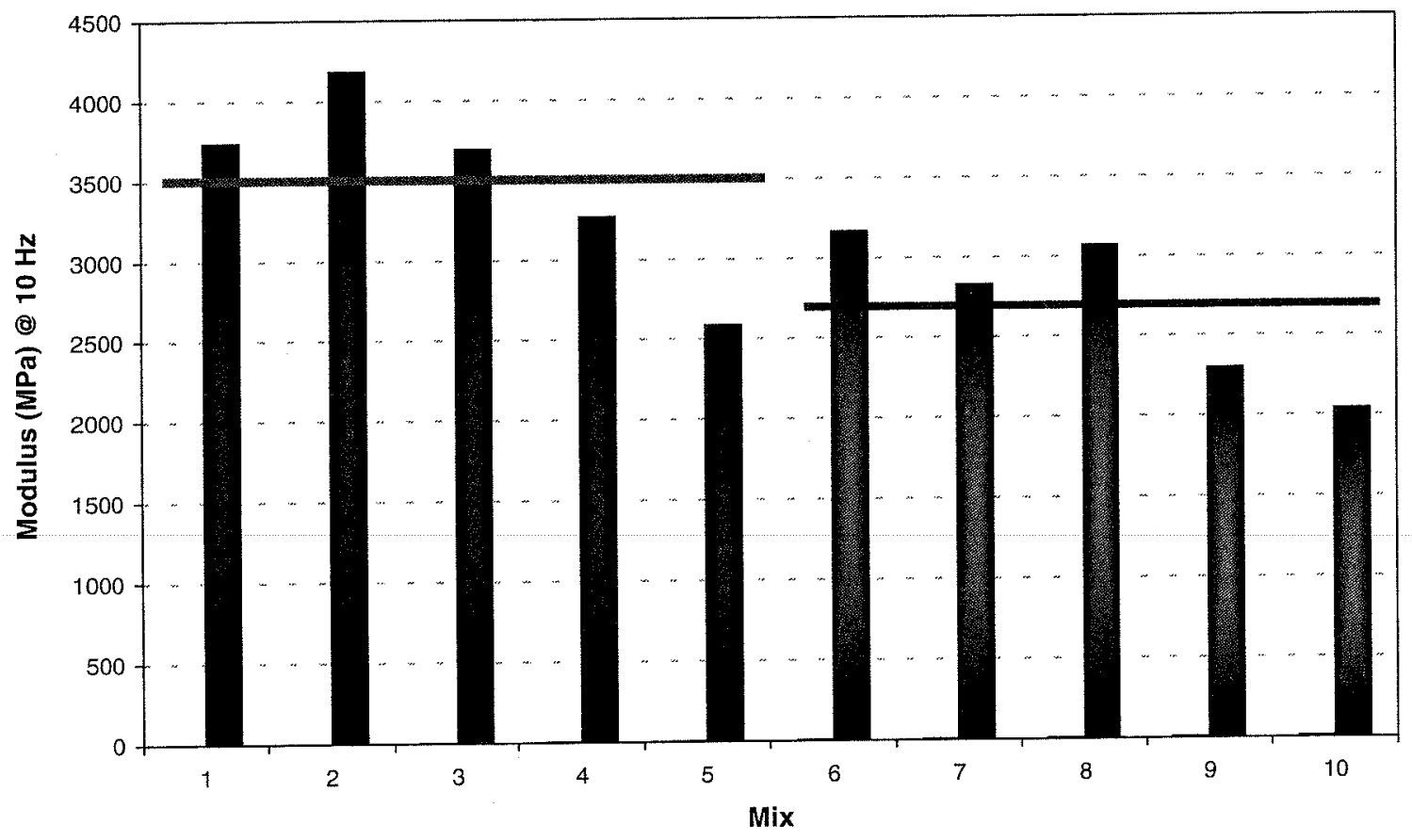

Figure 4. Stiffness modulus at $10 \mathrm{~Hz}$.

Figure 3 presents stiffness modulus of all mixes as a function of applied frequency. As expected this relationship follows a linear trending when the logarithm phase angle is plotted against the logarithm of the stiffness modulus. In Figure 4 the stiffness modulus at $10 \mathrm{~Hz}$ is plotted to shows the ranking of studied mixes and it can be concluded that the increase of fines increases the stiffness modulus. The horizontal lines represent the average value for each type of mix.

Figure 5 presents the phase angle of all mixes as a function of applied frequency and in Figure 6 the phase angle at $10 \mathrm{~Hz}$ is plotted to shows the ranking of studied mixes and it can be concluded that the increase of fines decreases the phase angle. The horizontal lines represent the average value for each type of mix. 


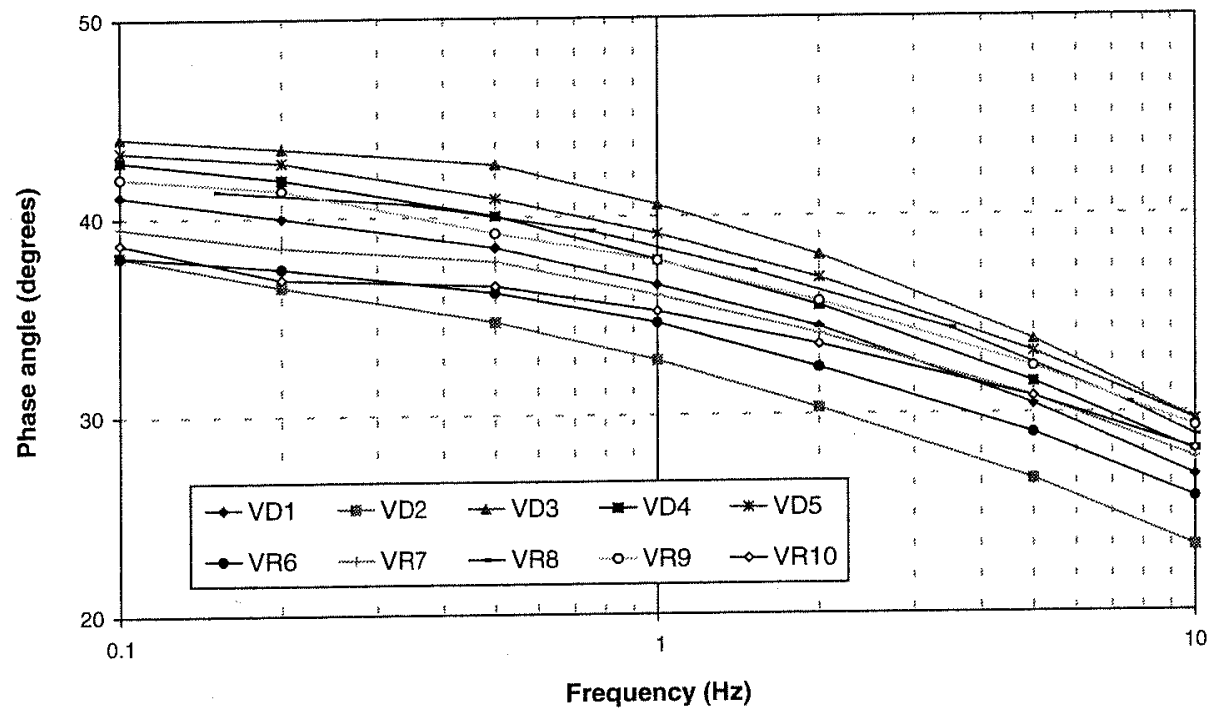

Figure 5. Phase angle plotted against frequency.

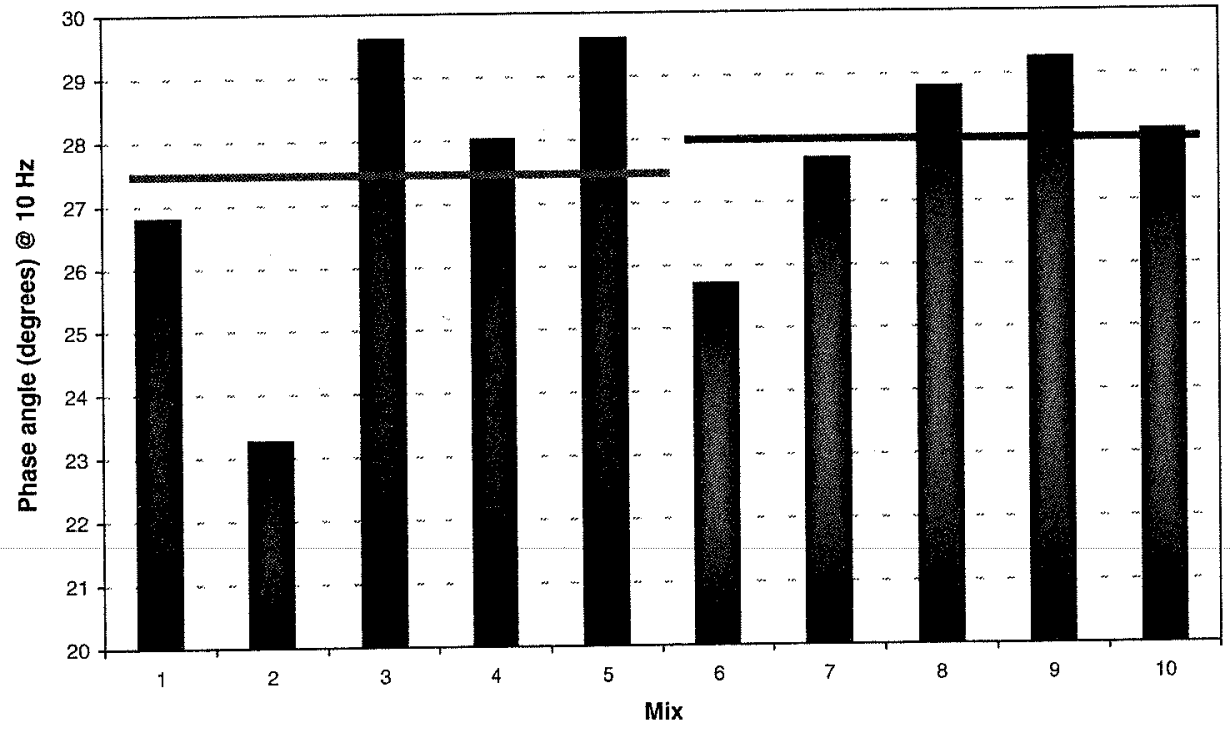

Figure 6. Phase angle at $10 \mathrm{~Hz}$.

\section{FATIGUE LIFE}

One of the major modes of distress considered in the asphalt concrete pavement design is the fatigue cracking. When an asphalt pavement layer rests on an untreated aggregate base layer, the passage of a wheel load causes the pavement to deflect.

The resistance to fatigue of a bituminous mixture is the ability to withstand repeated bending load without failure. This form of distress manifests itself by the appearance of cracking in the pavement surface. The fatigue of a bituminous mixture has been directly associated with the repeated application of tensile stresses or strains and it is generally accepted that it can be very well evaluated by a four point bending test (Pais, 1999). Fatigue tests are performed imposing strain or stress repetitively until failure occurs. The fatigue life is characterized by the relationship between the strain level and the number of repetitions to reach the mixture failure. 


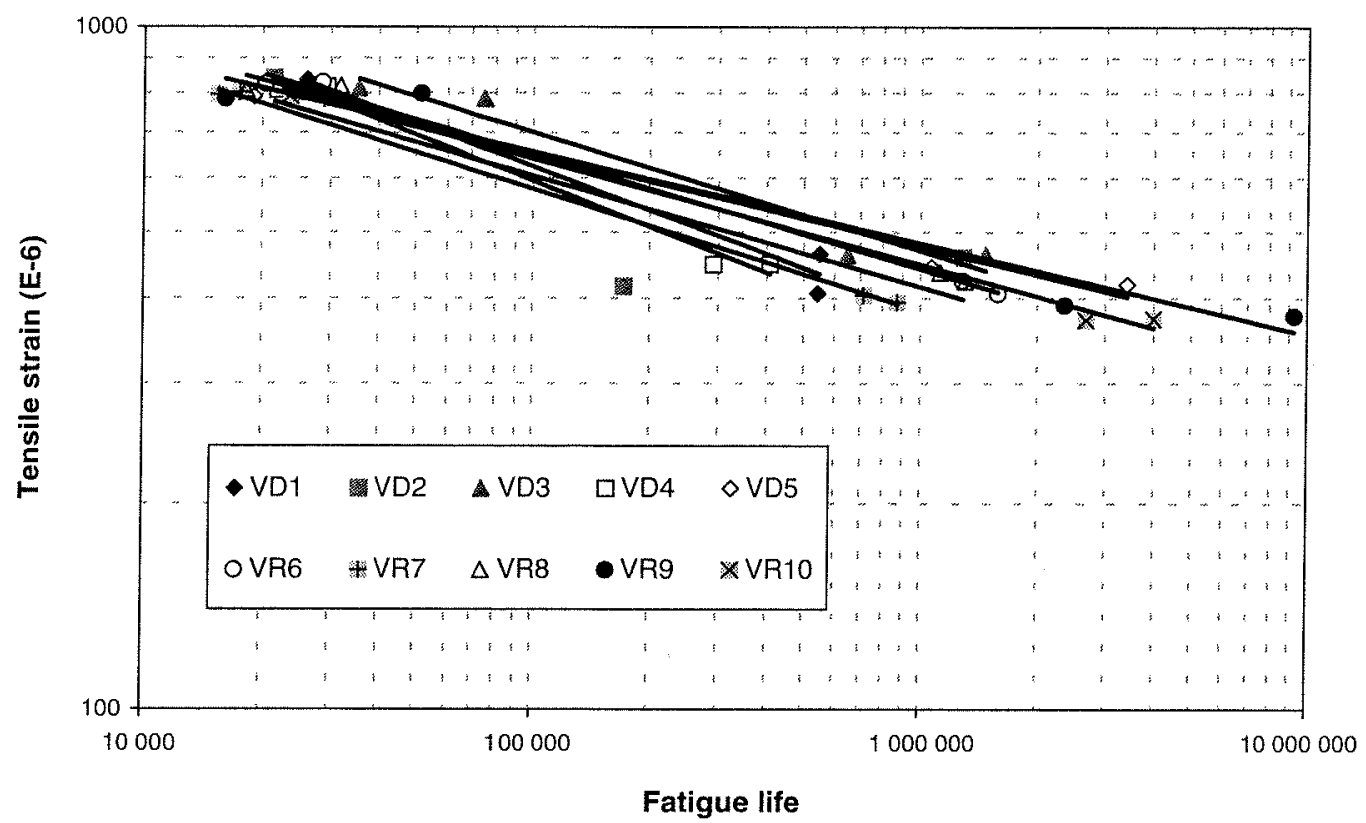

Figure 7. Fatigue curves for all mixes.

The mode of loading influences the mixture performance and controlled stress versus controlled strain is applied as a function of pavement structure (i.e., pavement thickness and stiffness). The repetitively applied loads usually follow a sinusoidal pattern although the traffic pavement response seems to be different.

The fatigue life of bituminous mixtures is influenced by several factors such as test temperaturc, frequency of applied loads. Aggregate gradation has an important effect on fatigue life as demonstrated by Sousa et al. (1998).

Fatigue cracking occurs gradually with cumulative straining of the pavement. The traditional approach based on a strain criterion has been used. However, the dissipated energy concept more accurately describes fatigue failure in dense graded bituminous mixtures.

A fatigue model has been established using a linear regression between fatigue life logarithm, $\log$ Nf, and the initial strain $\operatorname{logarithm}, \log \varepsilon$ t, for controlled strain tests. The fatigue model is as follows:

$$
N=c\left(\frac{1}{\varepsilon_{\mathrm{t}}}\right)^{d}
$$

where $N=$ the number of repetitions to failure, $\varepsilon_{t}=$ the tensile strain applied, $\mathrm{c}$ and $\mathrm{d}=$ experimentally determined coefficients.

To evaluate the bituminous mixture fatigue resistance, flexural fatigue tests were conducted according to the AASHTO TP8-94 (Standard Test Method for Determining the Fatigue Life of Compacted Hot Mix Asphalt (HMA) Subjected to Repeated Flexural Bending). They are intended to simulate pavement distress due to traffic loads during its expected design life. Fatigue Life is defined as the number of cycles until a $50 \%$ decrease of the initial stiffness of the test beam is achieved. Tests were executed at $20^{\circ} \mathrm{C}$ and at $10 \mathrm{~Hz}$ frequency rate of loading. Four fatigue tests were performed for each mix, two at a strain level of $800 \times 10^{-6}$ and to at $400 \times 10^{-6}$.

The fatigue curves of all tests are presented in Figure 7 where it can be observed the results of all fatigue tests. The ranking of these bituminous mixtures can be found in Figure 8 where the fatigue life at $100 \times 10^{-6}$ is presented. The analysis of this figure shows that the decrease of fine aggregates increases the fatigue life. 


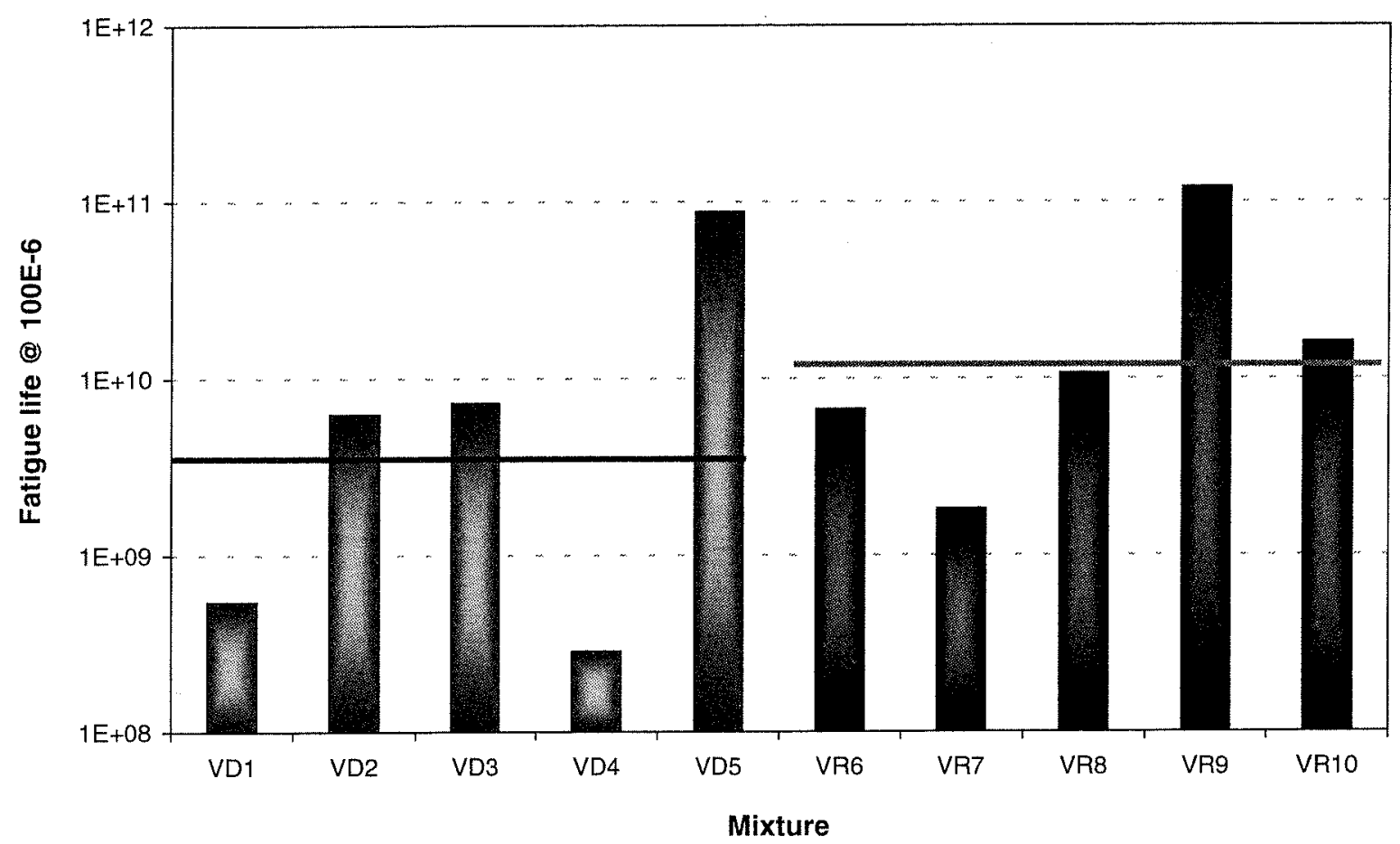

Figure 8. Fatigue life at a strain of $100 \times 10^{-6}$.

\section{PERMANENT DEFORMATION}

Permanent deformation in bituminous mixtures is primarily a plastic shear flow phenomenon at constant volume, occurring near the pavement surface, caused by the shear stresses occurring below the edge of the truck tires.

Also, intrinsically linked to this procedure is the assumption that most of the permanent deformation occurs on the hottest days with the heaviest trucks. This assumption stems from observations in the laboratory that bituminous mixtures exhibit strong plastic behavior described by a plasticity function that exhibits kinematics hardening. This hardening seems to be associated with the capability of the mixture to develop better particle-to-particle contact as it develops shear strains, and with the capability of the aggregate skeleton to develop dilatancy forces that in turn are capable of developing stabilizing confining stresses (Sousa, 1994).

This phenomenon appears to be best captured by the RSST-CH executed at the highest 7 day pavement temperature at $5 \mathrm{~cm}$ depth. One of the advantages of this test is that it does not cause any change in volume in the specimen during testing. This is particularly important because a mix's resistance to shear deformation should be measured with a test that does not cause any change in volume (densification or dilation) (Sousa, 1994).

The SHRP A-698 permanent deformation methodology to predict the accumulation of rut depth in asphalt concrete mixes was used and adapted, yielding the selection of adequate loading times, eventually to be used in the Repetitive Simple Shear Test at Constant Height for the prediction of rut depth.

RSST-CH testing was undertaken with 0.1 seconds loading times, plus a rest period of 0.6 seconds. For each bituminous mixture, 3 replicates were tested at $50^{\circ} \mathrm{C}$. The magnitude of the loading pulse was set at $70 \mathrm{kPa}$. The test temperature was chosen to be representative of the maximum average seven day temperature at $5 \mathrm{~cm}$ depth.

A procedure to estimate the permanent deformation of asphalt concrete pavement based on the RSST-CH test was developed (Sousa et al, 1993). Figure 9 diagrams a nomograph of the procedure. It is composed of four quadrants and it should be followed clockwise starting in Quadrant 1. 


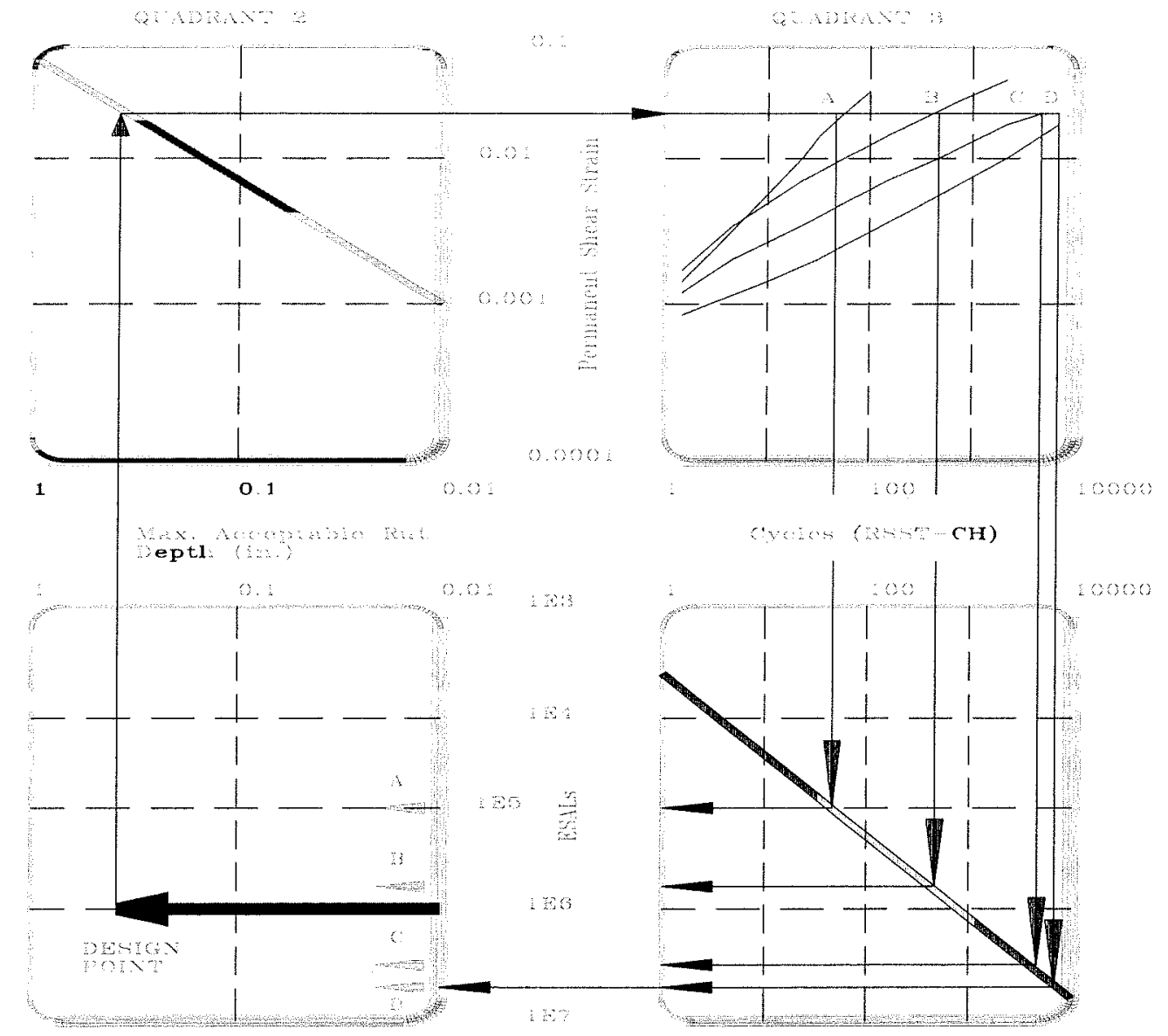

Figure 9. Nomograph procedure to estimate rutting performance.

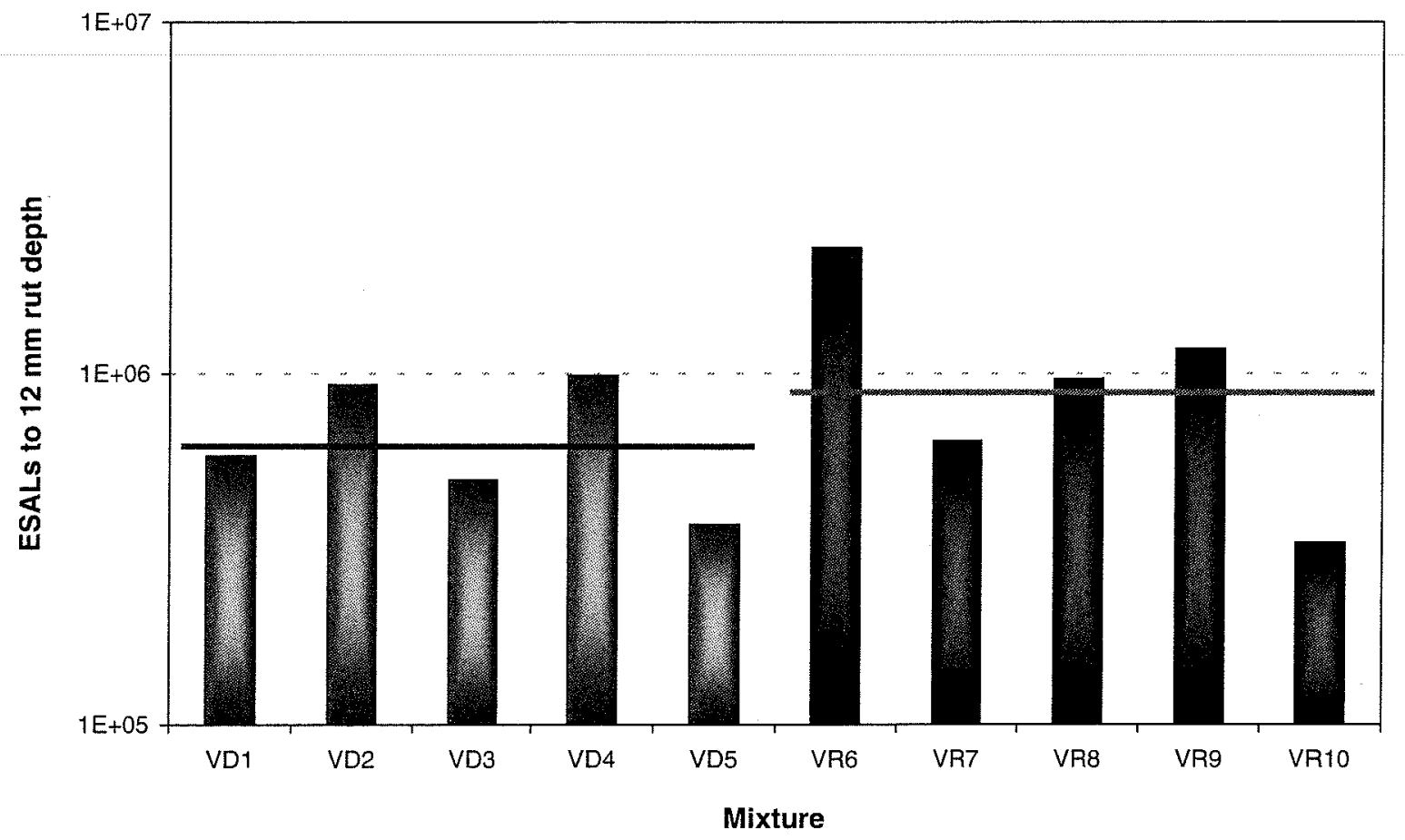

Figure 10. Permanent deformation test results. 
The procedure to estimate the permanent deformation starts by defining the rut depth level to be considered. The permanent shear strain, which is used to obtain the number of cycles in the RSST-CH, is calculated as following:

$$
\text { Rut depth }(\mathrm{mm})=279 * \text { Permanent Shear Strain }
$$

The number of ESALs is calculated using the following model:

$$
\log (\# \text { of cycles })=-4.36+1.24 \log (\# \text { of ESALs })
$$

The permanent deformation results for all bituminous mixtures, expressed in number of ESALs to reach $12.5 \mathrm{~mm}$ rut depth, are presented in Figure 10. It can be concluded that, in this case, the permanent deformation was influenced by the air-void content. The increase of the air-voidcontent increases the permanent deformation.

\section{CONCLUSIONS}

This paper presented a evaluation of the stiffness, fatigue and permanent deformation performance of bituminous mixtures with different aggregate gradation based on the gradation proposed by the Portuguese normalization for wearing course and base courses.

From this analysis, the following conclusions can be made:

- The increase of fine aggregates increases the stiffness modulus and decreases the phase angle;

- The decrease of fine aggregates increases the fatigue life;

- The permanent deformation is influenced by the air-void content. The increase of the air-voidcontent increases the permanent deformation.

\section{REFERENCES}

Duriez, M. 1950. Traité de Matériaux de Construction. Dunod. Paris.

Pais, J. C. 1999. Reflective Cracking in Flexible Pavement Overlay Design (in Portuguese). Ph.D. Thesis, University of Minho. Portugal.

Sousa, J. B., J. C. Pais, M. Prates, R. Barros, P. Langlois \& A. M. Leclerc, 1998. Effect of Aggregate Gradation on Fatigue Life of Asphalt Concrete Mixes. Transportation Research Board.

Sousa, J. B., S. L. Weissman, L. J. Sackman and C. L. Monismith. 1993. A nonlinear elastic viscous with damage model to predict permanent deformation of asphalt concrete mixtures. Transportation Research Record no. 1384, pp 80-93.

Sousa, J. B. 1994. Asphalt Aggregate Mix Design using the Simple Shear Test (Constant Height). Association of Asphalt Paving Technologists.

Tayebali, A. A., J. A. Deacon, J. S. Coplantz, F. N. Finn \& C. L. Monismith. 1994. Fatigue Response of AsphaltAggregate Mixes. SHRP-A-404, National Research Council, Washington, DC. 